\title{
Arkitekturax
}

\author{
Arkitekturax Visión FUA \\ ISSN: 2619-1709 | ISSN-e: 2665-105X \\ Publicaciones Universidad de América \\ Volumen 2, Número 2, enero-diciembre 2019, pp. 153-172 \\ https://doi.org/10.29097/26191709.265 \\ Web: https://revistas.uamerica.edu.co/index.php/ark
}

Revista internacional de arquitectura, urbanismo y políticas de sostenibilidad

\section{La transición de las ciudades: pasado, presente y futuro de la forma urbana}

\section{The transition of the cities: past, present and future of the urban form}

El artículo forma parte de los trabajos desarrollados para obtener el título de Magister en Gestión ambiental para la competitividad, en la Fundación Universidad de América

Sección: AMBIENTE • Artículo de investigación científica y tecnológica

Recibido: 15 de enero de 2019 • Aceptado: 19 de mayo de 2019

\section{Luis Fernando Molina-Prieto}

Arquitecto, M. Sc en Gestión Ambiental (c). Editor revista Arkitekturax. Docente investigador, grupo de investigación Territorio y Habitabilidad, Facultad de Arquitectura, Fundación Universidad de América, Bogotá D. C., Colombia. ORCID: https://orcid.org/0000-0002-3039-427X

Contacto: Imolinaprieto@gmail.com 


\begin{abstract}
Resumen
El artículo analiza el origen y la evolución de la forma urbana desde una variable bien definida: las transiciones. En la introducción se aclara que las transiciones estudiadas corresponden a dimensiones que superan el tradicional concepto de transición, el cual se limita al análisis del tránsito de lo rural a lo urbano. La metodología incluye cuatro momentos, siendo el cuarto la formulación de predicciones sobre las ciudades en 2050. Los resultados abordan tres temáticas: i) orígenes y evolución de las transiciones urbanas; ii) el futuro de las ciudades: referentes cinematográficos, y iii) las ciudades en 2050. Se concluye que las transiciones y la evolución de la forma urbana han tenido a lo largo de la historia estrechos vínculos, y precisamente, gracias a las transiciones las ciudades se consolidaron y evolucionaron hasta el estado actual, así como continuarán transformándose en el futuro.
\end{abstract}

Palabras clave: adaptación, transformación, innovación, modificación urbana.

\begin{abstract}
The article analyses the origin and evolution of the urban form from a well-defined variable: transitions. In the introduction it is clarified that the transitions studied correspond to dimensions that overcome the traditional concept of transition that only takes into account the transition from the rural to the urban. The methodology includes four moments, the fourth being the formulation of predictions about the cities of 2050. The results address three themes: i) origins and evolution of urban transitions; ii) the future of the cities: cinematographic referents; and iii) cities in 2050. It is concluded that the transitions and the evolution of the urban form have had close ties throughout history, and precisely, thanks to the transitions, the cities consolidated and evolved to the current state, and will continue to transform in the future.
\end{abstract}

Keywords: adaptation, transformation, innovation, urban modification.

\title{
Introducción
}

El origen y la evolución de la forma urbana pueden ser estudiadas desde distintos puntos de vista; entre estos enfoques, uno que no ha sido muy tenido en cuenta es el de las transiciones. El término transición se entiende como la «acción y efecto de pasar de un modo de ser o estar a otro distinto» (RAE, 23. ${ }^{a}$ ed.), e implica «definir el cambio, el traspaso, la evolución progresiva de un estado a otro» (Bembibre, 2011). Desde sus orígenes, la forma urbana requirió de las transiciones para desarrollarse, consolidarse, progresar y evolucionar. Conviene señalar que a lo largo de la historia las ciudades han sido moldeadas y transformadas merced a transiciones de distinta índole: climáticas, sociales, demográficas, políticas, económicas, culturales, militares, espaciales, de gobernanza, e incluso conceptuales e ideológicas, por solo 
mencionar unas cuantas. En su prolongado devenir las ciudades no han tenido una, ni dos, ni tres, sino incontables transiciones. De hecho, han sido tantas que se podría decir que la transición no es una variable, sino una constante de la forma urbana.

En la literatura se encuentran bastantes documentos relacionados con las transiciones urbanas, enfocados principalmente en las migraciones campo-ciudad. Pannell (2002) estudia las transiciones urbanas en China, entendiendo el término transición urbana como el movimiento de la población china desde las zonas rurales hacia las urbanas. De igual manera, Schmidt-Kallert (2009) comprende este concepto como la migración del campo a la ciudad; esta investigación analiza casos en Asia, África, la antigua Unión Soviética y América Latina. Por su parte, Rondinelli (1986), cuyo trabajo analiza cuatro países en desarrollo: Kenia, Corea del Sur, México y Panamá, enfoca su estudio en la relación entre la concentración de la población en las ciudades y el desarrollo de la agricultura. Otros autores asumen el concepto de transición urbana en este mismo sentido; así, por ejemplo, Martine y McGranahan (2010), en la investigación sobre la concentración de la población en las ciudades brasileñas, o McGranahan, Mitlin, Satterthwaite, Tacoli y Turok (2009), en el análisis sobre la concentración de la población en las ciudades africanas. Por otra parte, Nevens, Frantzeskaki, Gorissen y Loorbach (2013) proponen laboratorios de transición urbana - dándole otro alcance al término- que permitan establecer metodologías para agilizar la transición de las ciudades hacia la sostenibilidad. En este artículo se indagan otros enfoques de las transiciones urbanas, con el fin de detectar un elemento clave para el desarrollo de las ciudades contemporáneas: las transiciones. Finalmente, a partir del análisis de dicho elemento, se establecen una serie de predicciones concernientes a las ciudades del 2050.

\section{Metodología}

La investigación contó con cuatro momentos: i) elaboración del modelo de procedimiento, establecimiento de la ventana de tiempo e instrumento de análisis: se estableció como modelo de procedimiento la revisión sistemática de libros y artículos científicos; se fijó una ventana de tiempo que abarca, desde la finalización del último período glacial, hace más de nueve mil años, hasta el año 2050; y se dispuso la hermenéutica como instrumento de análisis; ii) obtención de conocimiento sobre el objeto de estudio: se realizó una búsqueda no aleatoria, sino sistemática de documentos que evidenciaran la importancia y trascendencia de las transiciones en la evolución y el devenir de la forma urbana; iii) análisis de la información e interpretación de los resultados; y iv) formulación de predicciones para las ciudades de 2050. 


\section{Resultados}

A continuación los resultados más importantes de la investigación.

\section{Orígenes y evolución de las transiciones urbanas}

Las primeras civilizaciones urbanas aparecieron sobre el planeta en regiones y momentos marcadamente distintos, pero merced a un único detonante: transiciones climáticas, ambientales culturales, económicas o sociales. Las más antiguas surgieron en el Viejo Mundo, y la transición que les dio cabida fue la finalización del último período glacial, hacia el 7000 a. C. Este cambio estableció condiciones favorables para la revolución agrícola, transformando vastos territorios de Europa y Medio Oriente - que permanecían helados o inhóspitos - en áreas apropiadas para el cultivo de trigo y cebada, y además, para el proceso de domesticación del ganado. Gracias a esa transición climática, que permitió la sedentarización y sentó las bases de la cultura, surgieron las primeras ciudades como se describe a continuación: 3000 años a. C., en el valle de inundación de los ríos Tigris y Éufrates, Ur, Eridu, Erech y Erbil, ciudades sumerias de crecimiento orgánico; 2600 años a. C., sobre las fértiles márgenes del río Nilo, Tel-el-Amarna, Kahun y Tebas, ciudades egipcias muy precarias en su componente urbano, construidas en su mayoría con un propósito específico: la construcción de las pirámides; y 2000 a. C., en la llanura aluvial del río Indo, Mohenjo-Daro, Harappa y Lothal, las primeras ciudades planificadas de las que se tiene noticia en el mundo, erigidas por la civilización de Harappa en la India (Morris, 1998). La transición en este caso, como ya se mencionó, fue climática.

Un poco más al oriente, en la Antigua China, las ciudades surgieron en el siglo XIII a. C., y fueron construidas por la primera dinastía que logró la unificación del país — la dinastía Shang_, que, además de ciudades, desarrolló la escritura, perfeccionó el vaciado en bronce e introdujo la innovación de los carruajes tirados por caballos. Las principales ciudades de la dinastía Shang fueron sus capitales: primero Yanshi, luego Zhengzhou y por último Anyang, y estaban ubicadas en el valle aluvial del río Amarillo (Botton Beja, 2000). La transición, para el caso de las ciudades chinas, fue socioeconómica, política y cultural. Conviene señalar que, a diferencia de las ciudades arriba mencionadas de Mesopotamia, Egipto e India, que actualmente son meras ruinas o importantes sitios arqueológicos, las ciudades chinas — al menos para los casos de Zhengzhou y Anyang — al igual que la cultura china, permanecieron activas desde sus orígenes hasta nuestros días.

En el siglo VI a. C. surgieron en el suroriente de Europa y en Asia Menor las ciudades-estado griegas. Se caracterizaron porque, «al menos en teoría, todos 
los ciudadanos tenían voz en los asuntos de la ciudad-estado» (Morris, 1998, p. 36). Dentro de estas ciudades de crecimiento orgánico, construidas como fortificaciones defensivas (amuralladas), se destacan: Atenas, Micenas, Tirinto, Olinto, Assos y Mileto. Para el caso de las ciudades griegas, la transición fue de carácter político. Pero hay algo muy importante que agregar: el urbanismo de la Antigua Grecia tuvo un cambio radical o una transición épica cuando los persas, en 479 a. C., invadieron, saquearon y arrasaron la ciudad de Mileto. Para la reconstrucción de la ciudad se convocó a un célebre arquitecto nacido precisamente en ella, Hipodamo de Mileto, quien, de manera inédita para la Grecia Antigua, pero no así para la India, planificó la ciudad a partir de una retícula espacial que determinó el trazado de las vías. El plan maestro para la nueva Mileto se transformó en referente obligado para los desarrollos y las formas urbanas de su época y de las épocas por venir (Morris, 1998). Dicho modelo, conocido en Colombia como «manzanas» y en Estados Unidos como blocks, aún forma parte de los principios básicos del urbanismo en todos los rincones del mundo. Los griegos empezaron a aplicar dicho modelo en las nuevas fundaciones, siendo una de las más destacadas la ciudad de Priene, muy cercana a Mileto. De modo que podemos hablar de otra transición en las ciudades griegas que impactó a Occidente: de las ciudades de crecimiento orgánico a las ciudades planificadas.

De forma casi paralela al desarrollo de la cultura y las ciudades griegas, surgieron la cultura romana y el Imperio romano. Su capital, la Eterna Roma, surgió y se consolidó como una ciudad de crecimiento orgánico, cuya origen data del año 753 a. C. (según la mitología, los fundadores de la ciudad fueron los hermanos Rómulo y Remo). Las primeras ciudades de la actual Italia se consolidaron de manera orgánica, pero, una vez la máquina de guerra desarrollada por el Imperio romano empezó a dominar y colonizar los territorios vecinos, desde España hasta el actual Irak, desde la actual Inglaterra hasta el antiguo Egipto, las ciudades que el imperio fundó a su paso siguieron el diseño de damero o cuadrícula del legendario Hipodamo de Mileto. De esta manera y gracias a los sofisticados mecanismos del aparato de guerra romano, la forma urbana planificada se extendió por el Viejo Mundo, puesto que los romanos fundaron innumerables ciudades a lo largo y ancho de su extenso imperio: Londinium (Londres), Barcino (Barcelona), Lutetia (París), Aquincum (Buda, parte de Budapest), Vindobona (Viena), Burdigala (Burdeos), Lugdunum (Lyon), Tolosa (Toulouse), por solo mencionar unas cuantas de las centenares de ciudades que erigieron los romanos. La transición en el caso de las ciudades fundadas por el Imperio romano fue, por una parte, militar y, por la otra, derivada del paso del crecimiento orgánico al desarrollo planificado. 
Tras la caída del Imperio romano en el siglo $\mathrm{V}$ de nuestra era y después de casi cinco siglos de oscurantismo, las ciudades resurgieron en Europa hacia los siglos X y XI. Durante la Edad Media muchas de las ciudades fundadas por los romanos fueron repobladas y reactivaron su actividad; otras evolucionaron de manera orgánica a partir de pequeños poblados, y un tercer grupo lo conformaron ciudades de nueva fundación. No obstante, aunque esos tres tipos de ciudades tenían orígenes y estructuras distintas, mantenían un elemento en común: la muralla con sus almenas, torres y puertas. De manera que la cara de las ciudades por aquella época no era precisamente acogedora. Y no estaban solamente en guerra comercial, pues eran muy frecuentes las guerras declaradas entre las distintas ciudades-estado, así como el saqueo y el pillaje entre ciudades. La transición, en el caso de las ciudades medioevales, se fundamentó en el terror y el miedo.

A partir del siglo XVI y hasta bien entrado el siglo XVIII, el Renacimiento transformó las ciudades europeas. Los dos elementos más sobresalientes de esta transición urbana fueron la caída de las murallas y la incorporación de la naturaleza en la ciudad. El Renacimiento se caracterizó por ser una época en la que las guerras y la violencia disminuyeron verticalmente, puesto que se empezaban ya a definir las naciones, y en consecuencia, la rivalidad entre ciudades-estado se redujo paulatinamente. Esta transición geopolítica culminó con la demolición de las grandes murallas que por siglos habían protegido a las urbes europeas. En muchos casos no se trataba de una muralla, sino de varios cinturones concéntricos de murallas, que fueron construidos a medida que las ciudades fueron creciendo y expandiéndose. El ejemplo más sobresaliente a este respecto es la ciudad de Brujas, en Bélgica, que contaba con cerca de siete cinturones de murallas protectoras, cada una con su respectivo foso. Tras la demolición de las murallas, Brujas se transformó en una especie de Venecia, aunque todos sus canales son artificiales y corresponden, en su gran mayoría, a los antiguos fosos que servían de protección (junto con las murallas) a la ciudad. Otro caso bien representativo de la transición es el de la caída de las murallas es el de París. Las murallas tenían un espesor de hasta 20 metros, de manera que, una vez las demolieron, entre 1660 y 1705, produjeron el espacio requerido para los famosos bulevares de la Ciudad Luz. La segunda transición que se generó en las ciudades europeas durante el Renacimiento fue la introducción de árboles y el diseño de jardines en las ciudades. Dice Morris (1998) al respecto, «para 1709 la operación de plantado intensivo de árboles y variedades vegetales estaba lo suficientemente avanzada como para que el sector fuera ya conocido por el nombre de Champs Elysées» (p. 225). Sin embargo, la gran transición de la ciudad renacentista alcanzó su pico más alto con la construcción de Versalles, puesto que 
con esta intervención, que dirigió el jardinero real, André Le Nôtre, se creó un concepto que transformaría radicalmente la calidad de vida en las ciudades: el concepto de parque. Una idea que fue emulada por doquier, de manera que existen enormes jardines para la realeza en incontables ciudades de Europa. Esta transición de las ciudades renacentistas europeas se podría llamar: de la calle al parque.

No fue hasta la Revolución Industrial que aconteció otra transición urbana. Con la creación de la industria (alimentada por carbón) y la ciudad industrial, la calidad de vida de los habitantes y la calidad de los elementos ambientales se deterioró de manera crítica. Los factores detonantes de esta transición fueron: aumento de la población urbana, cambios totales en las técnicas de producción, concentración económica, incorporación de las nacientes industrias a los enclaves urbanos, alta densidad demográfica y enorme extensión de los nuevos barrios obreros. El siguiente texto, escrito por Federico Engels, describe las condiciones ambientales de Mánchester en 1845:

\begin{abstract}
Abajo, junto al río, hay muchas curtiembres que llenan todo el barrio con el olor a putrefacción animal [...] Abajo corre, o mejor dicho está estancado el Irk, un río estrecho y negro, hediondo, repleto de desechos y residuos que bañan la orilla derecha, más baja. [...] En la parte superior del puente hay grandes curtiembres; más arriba aún, tintorerías, moledoras de huesos y gasógenos, cuyos canales de desperdicios se vierten todos en el Irk, el cual recoge, además, el contenido de las letrinas y las cloacas cercanas. (Engels citado por Benévolo, 1994, pp. 44-45)
\end{abstract}

Esta situación no era exclusiva de las ciudades inglesas. En el siglo XIX las epidemias de cólera y otras enfermedades se convirtieron en plagas que azotaban a los habitantes urbanos de todos los rincones del mundo. El hacinamiento en los barrios obreros, junto con la carencia de sistemas de alcantarillado y la ausencia de sistemas para la recolección de basura en las ciudades de aquella época, fue uno los principales factores que desencadenó esta crisis de salud pública global. Y fue precisamente desde las ciencias de la salud que se planteó la solución: el higienismo¹. Con esta solución surgieron los primeros estándares para la correcta ventilación e iluminación de los espacios arquitectónicos, así como las primeras recomendaciones para el saneamiento ambiental urbano, por ejemplo, la construcción de alcantarillados

1 «El higienismo, una palabra hoy en desuso y que poco significará para la mayoría de los lectores, fue a lo largo de la pasada centuria una poderosa corriente de pensamiento dentro de las ciencias médicas. Como campo de indagación científica, en el higienismo confluye una preocupación genérica por la salud pública, el intento de explicar el origen y mecanismos de determinadas enfermedades endémicas y epidémicas, y una reflexión amplia sobre lo que hoy llamaríamos la “calidad de la vida”» (Urteaga, 1985, p. 417). 
entubados y subterráneos. Fue una transición hacia el saneamiento ambiental y hacia la ingeniería sanitaria, que dio pie para las primeras regulaciones urbanísticas de la historia e impulsó las grandes transformaciones urbanas de las ciudades europeas a partir de 1848, dentro de las que se destacan: las grandes transformaciones urbanas de Haussmann en París (1853-1869); las de Anspach en Bruselas (1867 -1871); la construcción del Ring de Viena (a partir de 1857); la ampliación de Barcelona (desde de 1859); la ampliación de Florencia (1864-1877), y las transformaciones del Gran Londres (1848- 1865) (Benévolo, 1994). Todas ellas no fueron otra cosa que la materialización de los principios del higienismo y del urbanismo moderno. Conviene subrayar que Haussmann, para lograr sus objetivos, ${ }^{2}$ ideó y utilizó por primera vez en la historia de las ciudades el concepto de expropiación. Así logró realizar todas las grandes reformas de París, expropiando las propiedades a los legítimos poseedores y dueños de los inmuebles por donde pasarían las nueva y amplias avenidas; como consecuencia de ese proceso, surgió un cinturón de miseria en torno a la ciudad, donde se reunieron de manera espontánea las víctimas de ese atropello que se realizó en nombre del desarrollo urbano.

Lo que siguió a continuación no fue una transición, sino una ruptura. Dos guerras mundiales que no solo sacudieron al mundo, sino que arrasaron con innumerables centros urbanos. Muchas ciudades, especialmente las polacas, inglesas, holandesas, alemanas y japonesas, fueron devastadas por los bombardeos con dinamita, bombas incendiarias y atómicas. Esta violenta ruptura abrió el camino a otra transición: el urbanismo funcionalista.

En el ínterin entre las dos guerras mundiales, se celebró en Atenas el IV Congreso Internacional de Arquitectura Moderna (CIAM), y como parte de las conclusiones de ese importante evento, se publicó la Carta de Atenas, documento que recoge, a grandes rasgos, el pensamiento del arquitecto y urbanista suizo Le Corbusier. Cabe subrayar que Le Corbusier llamó a la ciudad la «máquina de habitar», puesto que confiaba en que la tecnología de aquella época, naciente y que empezaba a permear gran parte de las esferas de la vida, sería suficiente para dar solución a todas las problemáticas de la humanidad. Esperanza muy ligada al futurismo italiano, que lideraban Umberto Boccioni y Tommaso Marinetti, un movimiento intelectual y artístico muy difundido en las primeras décadas del siglo XX por Europa, pero que con el paso de los años demostró toda su inoperancia y vacuidad. Hoy sabemos que las máquinas no solo aportaron nuevas problemáticas,

2 Entre los cuales se debe tener muy en cuenta la destrucción de la resistencia y de las barricadas que, en los vericuetos de las calles medievales, le hacía el pueblo a Napoleón III. 
sino que no lograron solucionar los problemas fundamentales de la humanidad: hambre, miseria, ignorancia e inequidad.

De manera esquemática se puede decir que Le Corbusier, en la Carta de Atenas, proponía dos grandes transiciones para la ciudad. En primer lugar, considerar el incremento del tráfico automotor masivo como determinante principal para el diseño, rediseño o planificación de las ciudades del siglo XX, y por otra parte, la separación de las áreas residenciales con respecto a las industriales y las recreativas. Con la Carta de Atenas nació una idea que más adelante se aplicaría en la mayoría de las grandes ciudades del mundo: el Zoning (Castrillón y Cardona, 2014). Esta noción hacía eco de las cuatro funciones que Le Corbusier asignó a los seres humanos: habitar en los barrios residenciales; trabajar en las zonas industriales; recrearse los domingos en los parques y zonas verdes, y circular por las vías y autopistas al trasladarse de una zona a otra. Este esquema simplista y reduccionista de la ciudad y de la vida logró imponerse en muchas ciudades del mundo, trazando una especie de fronteras invisibles entre esas cuatro zonas urbanas, e incrementando la dependencia del automóvil para los urbanitas. Podemos entonces afirmar que la transición en las ciudades de posguerra fue de la ciudad destruida por los bombardeos a la ciudad zonificada en tres grandes áreas, caracterizadas por condiciones y características bien distintas, que estaban conectadas por una densa red de vías vehiculares.

En 1955, la decisión tomada por el director de planeación de la ciudad de Nueva York, Robert Moses (devoto del Zoning), que consistía en abrir una nueva vía a través de un barrio consolidado, el Greenwich Village, recurriendo al sistema de expropiación, desencadenó otra transición urbana: desde el Zoning que marginaba, separaba y creaba espacios inhóspitos, hacia el urbanismo vibrante, social y comunitario que planteó Jane Jacobs. Una habitante del sector, al ver amenazada su vivienda, organizó su comunidad y logró ganarle el pulso a Moses, quien, al ver frustrado su gran proyecto de intervención urbana, se vio obligado a renunciar a su cargo. Jane Jacobs escribió varios libros, dentro de los que se destaca The death and life of great american cities (1961). En ellos cuestionó profundamente el diseño urbano convencional, el de Haussmann, el de Le Corbusier, que priorizaba la ciudad en detrimento del ciudadano. El enfoque de Jacobs transformó la manera de ver, estudiar y planificar las ciudades, puesto que ella no veía en los andenes unas simples cintas de concreto para la circulación peatonal, sino lugares para el contacto con los otros, o ambientes que utilizaban los niños, y que por tanto, los exponían a malas compañías y malas influencias. Jacobs, además, fue la primera persona que hizo énfasis en la importancia de la diversidad, no solo en lo concerniente a la mezcla 
de usos urbanos (que contradice la teoría del Zoning y vaticina la ciudad compacta, que a finales del siglo XX propondría el arquitecto español Salvador Rueda), sino en cuanto a diversidad entendida como mezcla étnica y cultural (adelantándose casi medio siglo a las propuestas del arquitecto inglés Charles Landry y del economista norteamericano Richard Florida).

A partir de la década de 1970 las ciudades pasaron por una muy importante transición que aconteció por efecto de tres factores básicos: la crisis del petróleo, que le reveló al mundo su dependencia de los combustibles fósiles; el evidente daño a los ecosistemas y a la biodiversidad, que para esa década había sido plenamente documentado, y finalmente, los potenciales efectos de la superpoblación del planeta. Cabe destacar que, al respecto, ya se habían publicado: Our plundered planet (1948), en el que el geólogo y paleontólogo estadounidense Henry Fairfield Osborn denuncia la destrucción y el saqueo sistemático del planeta; Silent spring (1962), de la bióloga norteamericana Rachel Carson, que analiza el efecto negativo de los pesticidas sobre el ambiente, especialmente el DDT, que fue utilizado para cultivar los grandes volúmenes de alimentos requeridos por las ciudades; Avant que ñaure meure (1965), del ornitólogo francés Jean Dorst, quien puso en evidencia los daños ambientales de su tiempo, mediante estudios científicos rigurosamente elaborados; The population bomb (1968), del entomólogo estadounidense Paul R. Ehrlich, en el que predice los efectos catastróficos que la superpoblación tendrá sobre el planeta, y Los límites del crecimiento (1972), trabajo encargado por el Club de Roma ${ }^{3}$ al MIT ${ }^{4}$. En esta obra, Meadows, Meadows, Randers y Behrens, concluyeron que el planeta y sus recursos son finitos, por lo que, en consecuencia, el desarrollo no puede ser ilimitado. Dicho de otra forma, insistieron en que el desarrollo «requiere de límites», de ahí el título del documento. Todos esos antecedentes generaron una gran transición en las ciudades, que inicialmente tomó la forma de investigaciones y propuestas teóricas ${ }^{5}$ y experimentos aislados ${ }^{6}$; pero que décadas después empezó a materializarse en proyectos arquitectónicos y urbanos de gran y pequeña envergadura.

Para la década de 1980 el daño al ambiente era tan evidente que la Comisión de Desarrollo y Medio Ambiente de la Naciones Unidas dio a conocer el

3 Organización no gubernamental fundada en 1968 en Roma por personas preocupadas por salud del planeta.

4 Massachusetts Institute of Technology.

5 En energía alternativas y sistemas constructivos amigables con el ambiente.

6 Como Arcosanti, la utópica ciudad de Paolo Soleri en Arizona. 
documento Our Common Future, también llamado Informe Brundtland (apellido de la presidenta de dicha comisión, la política noruega Gro Harlem Brundtland). En dicho informe se concluyó que la humanidad tiene la capacidad para lograr un desarrollo sostenible, el cual se definió como aquel que garantiza la satisfacción de las necesidades de la generación presente sin comprometer la capacidad de las generaciones futuras para satisfacer sus propias necesidades.

A partir del concepto de desarrollo sostenible las ciudades empezaron una nueva transición: dejaron de ser meros juguetes de urbanistas vanidosos y egocéntricos, que solo deseaban hacer una escultura habitable y memorable, para transformarse - al menos conceptualmente- en contenedores de seres humanos en los que se deben tener en cuenta factores ambientales, económicos y sociales para su sustentabilidad. La transición en esta década llevó a las ciudades desde la mesa de dibujo y el taller de maquetas de los arquitectos, hasta un laboratorio multidisciplinar posmoderno que trascendió las búsquedas meramente estéticas o funcionales, para intentar un trabajo por el verdadero bienestar de todos los urbanitas.

En la década de 1990, el arquitecto español Salvador Rueda difundió su teoría de la ciudad compacta, cuestionando a muchísimas ciudades que se habían estructurado a partir del Zoning; la propuesta llamó la atención sobre la sustentabilidad del modelo de ciudad tradicional mediterránea: compacta, caminable, con mezcla de usos, con diversidad social y cultural. En la misma década, el arquitecto inglés Charles Landry (1995) publicó sus ideas sobre la ciudad creativa, ideas que en el siglo XXI florecerían en forma de numerosas investigaciones relacionadas con los aspectos sociales y económicos de las ciudades. Asimismo, el economista norteamericano Jeremy Rifkin (1994) popularizó sus ideas sobre la automatización del trabajo y los efectos que esto tendría sobre la población urbana, especialmente en relación con las clases trabajadoras.

En este siglo los estudios de la ciudad desde otras disciplinas se hicieron frecuentes: Landry $(2000,2005)$ continuó profundizando en el tema de las ciudades creativas, en tanto que el economista inglés John Howkins (2002) publicó los fundamentos de la economía creativa (conocida en Colombia como Economía Naranja). A partir de esos dos autores se generó una oleada de publicaciones sobre la economía y la ciudad creativa, que empezaron a dar forma a un nuevo paradigma para el diseño y la planificación urbana; paradigma que se impuso primero en Norteamérica, con Richard Florida (2002, 2005, 2007, 2009); luego en América Latina, con Fonseca y Kageyama (2009), y finalmente en Europa, con Anderson, Anderson y Mellander (2011). 
Desde otras esferas, aparte de la económica, también surgieron nuevos retos de ciudad. Uno de ellos lo planteó el profesor inglés de geografía humana Neil Adger (2006), quien evidenció tres factores que determinan la actual vulnerabilidad de las ciudades: i) falta de preparación ante catástrofes naturales, ii) ausencia de estrategias de adaptación urbana de cara al cambio climático y iii) falta de políticas claras frente a la alimentación de la creciente población mundial. Adger vinculó la mitigación de estos riesgos a variables marcadamente socioeconómicas y culturales. La ciudad, entonces, vivió otra transición: de la vulnerabilidad urbana hacia el paradigma de la resiliencia urbana.

Frente a los riesgos de inundación y en relación al acceso de los urbanitas al agua potable —-solo dos de los muchos efectos del cambio climático—-, surgieron nuevos paradigmas: en Escocia, los Sistemas Urbanos de Drenaje Sostenible-SUDS (CIRIA, 2000), y en Australia, el Diseño Urbano Sensible al Agua (Australian Government, 2006). Además, en Australia también nació el concepto de ciudades sensibles al agua (Brown, Keath y Wong, 2009), una política pública que supera el objetivo de controlar las inundaciones, puesto que abarca componentes ambientales, educativos y culturales, socioeconómicos y de gobernanza, de diseño urbano e hidráulico. Un paradigma que ya trascendió las fronteras de Oceanía y que cuenta con una sólida base sociopolítica y cultural, que son las comunidades «sensibles al agua», puesto que son ellas las que aportan sostenibilidad al concepto, merced a sus comportamientos respecto a las fuentes de agua y a su injerencia en la toma de decisiones. Conviene señalar que este concepto se basa en la descentralización y la autonomía en lo concerniente al acceso al agua (CRCWSC, 2014).

La autonomía, junto con el cuidado del ambiente, también se advierte en las nuevas tendencias de agricultura urbana y de techos verdes, actualmente requeridos en toda obra arquitectónica por Toronto (Canadá), Recife (Brasil) y París (Francia) y profusamente extendidos en Sídney y Melbourne (Australia), Berlín, Dusseldorf, Stuttgart y Múnich (Alemania) (con un total de 86 millones de $\mathrm{m}^{2}$ de techos verdes), Shanghái y Beijín (China), Chicago, Nueva York, Portland, Filadelfia, Seattle y Washington (Estados Unidos), Londres (Reino Unido), Basilea (Suiza) y Singapur (República de Singapur) (Molina-Prieto, 2016).

Autonomía y nuevas formas de integración social (el «tercer sector») también se aprecian en los Jichikai o Chokai japoneses, que son asociaciones de vecinos de un mismo barrio o una misma comunidad que se organizan con el fin de colaborarse mutuamente. El Jichikai puede ayudar a un vecino cuando sufre una calamidad, o cuando se encuentra desempleado, lo que no excluye la organización 
de actividades comunitarias que incrementen el tejido social y el sentido de pertenencia por el barrio y su espacio público (Rifkin, 1994).

De manera que la transición actual transita tres senderos bien diferenciados: i) el necesario fortalecimiento de los lazos comunitarios entre urbanitas, para hacer frente a la inequidad y a la brecha económica que cada día aísla y separa más a los ricos de los pobres; ii) autonomía en cuanto a gestión del agua, la energía y algunos alimentos, rompiendo con la dependencia que por tradición se ha tenido con el Estado centralizado, y iii) resiliencia como estrategia de adaptación frente al cambio climático y el crecimiento demográfico.

Una transición que llevará a las ciudades desde las estrechas miras de arquitectos y urbanistas, hacia la multi y la transdisciplinareidad en la planificación y el ordenamiento urbano, que es una visión multifactorial que superará con creses los problemas espaciales de las ciudades y que se adentrará en las multifacéticas problemáticas urbanas: socioculturales, étnicas, demográficas, de género, tecnológicas, alimentarias, biológicas, hídricas, energéticas, entre otras muchas.

Por último, conviene decir que gracias a la transición actual las ciudades del siglo XXI no serán más ese sencillo contenedor urbano en el que simplemente «se solía habitar», pues las ciudades están empezando a ser ese lugar donde confluyen y convergen todas las facetas que como humanidad y como seres humanos tenemos tanto en la práctica como en potencia. Quizá en un futuro no muy lejano, la humanidad logre finalmente, florecer.

\section{El futuro de las ciudades: referentes cinematográficos}

Las visiones más acertadas del futuro de las ciudades se han realizado desde el séptimo arte. Es posible que los directores de las películas que se mencionan a continuación pertenecieran a una generación de cineastas que se distinguían por conocer muy de cerca la cultura y la naturaleza humanas, de ahí, pues, las sutiles y profundas miradas que hacen del futuro urbano. La primera película que abordó este tema fue Metrópolis (Pommer y Lang, 1927), del director alemán Fritz Lang, y se destaca porque identificó con claridad cuatro aspectos de las formas urbanas del futuro: i) los autos voladores; ii) la esclavización y mecanización del trabajo humano; iii) la enorme desigualdad entre ricos y pobres, y iv) la concentración de la riqueza del planeta en unas pocas personas. Esta cinta paradigmática, que todo estudiante de arquitectura debería ver, sentó las bases de un cine de ficción y prospección que no vería el futuro con esperanza, porque al parecer, su director conocía muy de cerca las sombras más oscuras de la naturaleza humana. 
Películas más recientes, como Blade Runner (Deeley, Fancher y Scott, 1982), del director británico Ridley Scott, o El quinto elemento (Ludoux y Besson, 1997) del director francés Luc Besson, permiten otras aproximaciones a las particularidades de las ciudades del futuro. Estas dos cintas coinciden con Metrópolis en las cuatro cualidades arriba mencionadas (de manera que no las repetiré), pero añaden, otras cinco. Continuando la secuencia numérica, tendríamos: v) la conquista de otros planetas y su aprovechamiento por los humanos como marco general del futuro urbano; vi) la ausencia de auténticas relaciones sociales en las ciudades; vii) la vida solitaria de los adultos en habitáculos individuales — similares a los concebidos y construidos en Tokio por los arquitectos del metabolismo japonés en la década de 1970_- viii) la atmósfera hipertecnológica que envuelve a los urbanitas del futuro; y ix) un poder centralizado que lo controla todo, desde la tecnología y los androides o replicantes, pasando por la economía, hasta abarcar la vida íntima de cada uno de los habitantes del planeta.

Otra película que coincide en la existencia de un poder central, con Blade Runner y con El quinto elemento, es Brazil (1985), del director británico Terry Gilliam. Brasil es una mirada al futuro muy pesimista. Una película inmersa en un ambiente caótico en el que los atentados terroristas — en contra del poder centralson pan de cada día. Pero aparte de su visión sociopolítica conflictiva y desastrosa, Brazil aporta una décima característica visionaria a las ciudades del futuro: $\mathrm{x}$ ) todas las ciudades grandes, medianas y pequeñas se conurbarán hasta conformar una enorme e inacabable ciudad de la que nadie jamás podrá salir o entrar porque nunca acaba ni termina... Una especie de ciudad-cuenca ilimitada, que se riega como un enorme pulpo sobre los cinco continentes. Una visión que el arquitecto y teórico norteamericano Charles Jencks ya había vaticinado para el siglo XXI en su libro Arquitectura 2000 predicciones y métodos (1971), es decir, la conurbación global.

Por otro lado, y para concluir con los referentes cinematográficos, vale la pena mencionar la cinta Mad Max (Kennedy y Miller, 1979), del director australiano George Miller. Una visión posapocalíptica de un planeta Tierra donde ya no existen ciudades, ni tecnología ni cultura, porque la Tercera Guerra Mundial acabó con todo. Esta perspectiva, no se tiene en cuenta en adelante. Puede que la Tercera Guerra mundial estalle, pero no creo que acabe con todo.

\section{Las ciudades en 2050 (predicciones)}

La estructura gris de las ciudades, es decir, las obras civiles y arquitectónicas adquirirán una nueva dimensión gracias a los nanomateriales (nanosílice, nanomagnetita, 
nanotrióxido de aluminio, nanotubos de carbón, grafeno, entre otros), puesto que, agregados a materiales tradicionales como el concreto o el acero, incrementan su plasticidad, resistencia mecánica y durabilidad. Así, con menos material se lograrán estructuras más sólidas y resistentes a esfuerzos como la compresión, la flexión, la tracción, la torsión y el corte (Molina-Prieto y Garzón Castellanos, 2017). De otro lado, algunos materiales compuestos revolucionarán la industria de la construcción de edificaciones, como, por ejemplo: i) compuestos de matriz metálica, utilizados actualmente en la industria aeroespacial por su gran resistencia mecánica y poco peso, así como por estar conformados principalmente por cuatro metales ligeros: aluminio, titanio, magnesio y berilio; ii) compuestos de matriz cerámica, caracterizados por su alto desempeño térmico y por soportar temperaturas de hasta de 1800 ${ }^{\circ} \mathrm{C}$ (se usan en turbinas de aviones y cohetes y en plantas de generación de energía para las industrias), así como por sus componentes primarios: silicio, dióxido de silicio (o sílice), alúmina, calcio y sodio, y iii) de matriz orgánica, cuyas características físicas se clasifican en dos categorías: polímeros termoestables y polímeros termoplásticos, los cuales tiene propiedades adherentes y aislantes de gran valor en la industria actual por su alta durabilidad, escaso desgaste y adaptabilidad a diversas condiciones climáticas. Un ejemplo de estos materiales es el policarbonato, muy utilizado actualmente por la industria de la construcción (Molina-Prieto y Cortes Cely, 2014). Estos desarrollos tecnológicos renovarán el arte del diseño urbano y arquitectónico. Un asomo de esta transición lo evidencian las obras de la arquitecta árabe Zaha Hadid.

Además, la tecnología, especialmente, la biotecnología, establecerán una transición en el campo de las ciencias de la salud. La esperanza de vida seguirá expandiéndose, las enfermedades serán detectadas desde muy temprano (incluso, desde el vientre materno), y cuando algo ocurra, ahí estarán los nanorobots, inoculados en el torrente sanguíneo por medio de jeringas, para remediar las cosas desde adentro, librando batallas interiores, imperceptibles, pero que traerán salud a los pacientes tratados con estas tecnologías (claro está, a los que puedan costear tales tratamientos). La longevidad, que incluirá únicamente una parte de la población, tendrá una importante e impredecible injerencia en las ciudades del futuro.

No sobra decir que el campo de las comunicaciones continuará evolucionando de forma exponencial, de manera que el flujo de información en el 2050 no será un problema o una limitante. La tecnología también irrumpirá en la movilidad de las ciudades: automóviles, buses, aviones, trenes y tranvías autónomos, o sea, robotizados; lo mismo sucederá con muchos de los servicios que prestan las ciuda- 
des: meseros, locutores de radio, médicos, enfermeras. Los robots, especialmente los androides, serán parte de la vida cotidiana, y como lo predijo Blade Runner, serán los encargados de la exploración espacial. El viaje a Marte, para 2050, será historia. En esa década se estará trabajando en su terraformación, y las primeras oleadas de colonos se estarán instalando en el planeta rojo. Las ciudades empezarán su travesía interestelar. Por último, conviene subrayar que en 2050 la órbita terrestre, la de la luna y la de marte (y quizá la de otros planetas del sistema solar) rebozarán de estaciones orbitales: pequeñas ciudadelas cuya ingravidez, para esa época, ya no será un inconveniente.

Para 2050 serán muy pocas las ciudades que dependan de los pocos combustibles fósiles que aún se encuentren en el subsuelo. La transición a energías limpias ya habrá sido realizada por grandes potencias como China, India, Rusia, la Unión Europea y el Reino Unido. Es posible que Estados Unidas se haya fragmentado, o que sus estados más ricos y poderosos (California, Texas, Nueva York) mantengan una enorme independencia con relación al gobierno federal. Los estados independientes o autónomos ya habrán realizado dicha transición, pero quizá los más débiles y conservadores continúen insistiendo en el uso de los combustibles fósiles. El resto del mundo continuará en un lugar inferior, como el eterno subalterno que no tiene derecho a hablar, y que, si por casualidad se expresa, solo logra llenar el vacío que existe entre las palabras de los discursos globales (Spivak, 1988). De manera que no es posible hacer predicciones al respecto.

Como lo predicen Blade Runner y El quinto elemento, para 2050 el concepto de familia, como hoy en día se conoce, será una costumbre en vías de extinción. La composición familiar más común y numerosa será la unipersonal. La individualidad y la autonomía serán predominantes, de manera que no se requerirá para la vivienda sino de un espacio no muy grande, pero sí colmado de aparatos tecnológicos. La vivienda típica será similar a las cápsulas ingeniadas por Kenzo Tange y Kisho Kurokawa, líderes del metabolismo japonés en la década de 1970, pero ahora con los aportes de la supertecnología. Los robots especializados en acompañar a las personas, tanto a adultos mayores con limitaciones, como a jóvenes plenos de hormonas, serán una realidad palpable, y al decir palpable quiero decir que los avances en cuanto a la producción de piel artificial para esa década serán casi perfectos.

La economía del futuro será manejada por un puñado de individuos; el resto de los habitantes permanecerá en condiciones de semiescalvitud o esclavitud total, especialmente en América Latina, África y algunos países del sudeste asiáti- 
co. A nivel global, la economía de la gran mayoría será de mera supervivencia, y su recreación será virtual. Los parques y las grandes zonas verdes ya no existirán, puesto que habrán sido urbanizadas por efecto de la superpoblación del planeta. Claro que, en lugares vedados a la gran mayoría, se conservarán hermosos bosques, extensos campos de golf e islas paradisíacas, pero solo serán asequibles a una muy reducida minoría: la élite 2050.

La alimentación de los 9700 millones de habitantes que se calcula tendrá el planeta en 2050 será un reto mayor. Por supuesto que el hambre no desaparecerá, aunque así lo manifiesten los Objetivos del desarrollo sostenible 2030. Por el contrario, a mitad del siglo XXI los alimentos escasearán y muchos seres humanos permanecerán recostados en el umbral de la muerte por inanición. Los barrios informales de hoy, que actualmente son el 70 \% de la ciudad de Bogotá, por ejemplo, serán inmensos; los barrios de la élite serán muy pequeños y estarán protegidos, como en la Edad Media, por enormes murallas almenadas, pero ahora custodiadas por personal de seguridad público-privada armado con sofisticadas herramientas para matar. En esos guetos dorados, la vida será otra cosa. Y como acontece actualmente en algunos países de América Latina, los superricos saldrán de sus refugios amurallados en helicóptero (para ese tiempo, en autodrones). Las verduras se cultivarán en túneles junto con los miles de insectos que aportarán proteína y calorías a la inmensa mayoría; carne no comerán sino muy pocos.

Los ecosistemas estarán dañados severamente o totalmente destruidos. Los servicios ecosistémicos serán reemplazados por máquinas que limpian el aire, el agua o el suelo de agentes contaminantes, como ya se hace en algunas ciudades. Los elefantes, los rinocerontes, los tigres y los leones serán historia, o solamente se conservarán escasos individuos en cautiverio. El mar estará colmado de basura, carros viejos, neveras y lavadoras destartaladas. Las ballenas solo habitarán bajo las frías aguas del ártico, y cada vez que migren a aguas más cálidas para reproducirse serán asesinadas. Los urbanitas comunes y corrientes no sabrán con claridad qué es un lago, un río y mucho menos un humedal. La vida urbana será gris, árida, polucionada, insana, pero en esas inhóspitas ciudades habitará el 90 \% de la población.

\section{Conclusiones}

Las transiciones y la evolución de la forma urbana han tenido a lo largo de la historia estrechos vínculos; gracias a estas transiciones las ciudades se consolidan y evolucionan. Las transiciones urbanas surgieron por diversos factores: climáticos, 
socioeconómicos, políticos, culturales, entre muchos otros. En la Antigua Grecia se destaca la transición del crecimiento orgánico urbano a las ciudades planificadas. En la Edad Media se destacada la transición de ciudades perfectamente consolidadas hacia un estado de caos, terror y miedo. Durante el Renacimiento sobresale la transición que incluyó los parques, las áreas verdes y los árboles como parte del diseño urbano. La Revolución Industrial generó una gran transición urbana, que densificó notablemente la población de las ciudades y redujo de manera drástica la calidad de vida urbana. En las postrimerías del siglo XIX una transición, que surgió del campo de las ciencias de la salud, se insertó en los principios de la planificación urbana: el higienismo. En los albores del siglo XX surgió una transición que plantó su esperanza en que las máquinas lo solucionaran todo, y más adelante, en la década de 1960, otra que reaccionó frente al despotismo de los burócratas del planeamiento urbano, cuya responsable no fue otra que Jane Jacobs. A partir de la década de 1970 los conceptos de desarrollo sostenible y ciudad sostenible incubaron otra transición más: la búsqueda de la sustentabilidad urbana. Dos décadas después las ciudades entraron en otra transición: el paradigma de la ciudad creativa. Y en el presente siglo se destacan: la transición hacia la resiliencia urbana, el replanteamiento de la gestión de las aguas urbanas, la seguridad alimentaria que recurre a las granjas urbanas y el fortalecimiento del tejido social y la cooperación entre vecinos. Más allá de las transiciones identificadas y expuestas están las predicciones que plantea el artículo, algunas de las cuales son transiciones que ya se asoman en el horizonte.

\section{Referencias}

Anderson, D., Anderson, Á. y Mellander, C. (2011). Handbook of creative cities. Cheltenham, UK: Edward Elgar Publishing.

Australian Government (2006). Water sensitive urban design. Technical design guidelines for south east Queensland. Queensland: Australian Government.

Bembibre, C. (2011). Definición de transición. En Definición ABC. Recuperado de https://www.definicionabc.com/general/transicion.php

Benévolo, L. (1994). Orígenes del urbanismo moderno. Madrid, España: Celeste Ediciones.

Botton, F. (2000). China: su historia y cultura hasta 1800. México D. F.: El Colegio de México.

Brown, R., Keath, N. y Wong, T. (2009). Transitioning to water sensitive cities: historical, current and future transition states. En 11th International Conference on Urban Drainage. Conferencia presentada en Edinburgh, Scotland, UK.

Carson, R. (1962/2002). Silent spring. Nueva York, EE. UU.: A Mariner Book.

Castrillón, A. y Cardona, S. (2014). El urbanismo y la planeación moderna. Glocalidades en la formación de la modernidad urbana de Medellín. Historia y sociedad, 26, 17-51. DOI: https:// doi.org/10.15446/hys.n26.44383 
CIRIA. (2000). Sustainable urban drainage systems: design manual for Scotland and Northern Ireland. London: Construction Industry Research and Information Association.

Cooperative Research Centre for Water Sensitive Cities. (2014). Research 2012 to 2016. Melbourne: CRCWSC.

Deeley, M., Fancher, H. (productores), y Scott, R. (director). (1982). Blade Runner [cinta cinematográfica]. Estados Unidos: Warner Bros.

Dorst, J. (1965). Avant que nature meure. Lyon, Francia: Société Linnéenne de Lyon.

Ehrlich, P. (1968). The population bomb. Nueva York: Buccaneer Books.

Florida, R. (2002). The rise of the creative class: and how it's transforming work, leisure, community and everyday life. Nueva York: Basic Books.

Florida, R. (2005). Cities and the creative class. New York: Routledge.

Florida, R. (2007). The flight of the creative class: the new global competition for talent. Nueva York: Basic Books.

Florida, R. (2009). Who's your city? How the creative economy is making where to live the most important decision of your life. New York: Basic Books.

Fonseca, A., y Kageyama, P. (orgs.) (2009). Creative city perspectives. San Paulo, Brasil: Garimpo de Soluções.

Howkins, J. (2002). The creative economy: how people make money from ideas. Londres: The Penguin Press.

Jacobs, J. (1961). The death and life of great American cities. Madrid: Capitán Swing libros.

Jencks, C. (1971). Arquitectura 2000 predicciones y métodos. Barcelona, España: Blume.

Kennedy, B. (productor), y Miller, G. (director). (1979). Mad Max [cinta cinematográfica]. Australia: Mad Max Films.

Landry, C. (2000). The creative city. A toolkit for urban innovation. Londres: Earthscan.

Landry, C. (2005). Creativity and the city: Thinking through the steps. Recuperado de http://www. charleslandry.com/index.php?l=articles

Landry, C. y Bianchini, F. (1995). The creative city. Londres: Demos.

Ludoux, P. (productor), y Besson, L. (director). (1997). El quinto elemento [cinta cinematográfica]. Francia: Gaumont.

Martine, G. y McGranahan, G. (2010). Brazil's early urban transition: what can it teach urbanizing countries? (Urbanization and Emerging Population n. ${ }^{\circ}$ 4). Nueva York: International Institute for Environment and Development-IIED.

McGranahan, G., Mitlin, D., Satterthwaite, D., Tacoli, C. y Turok, I. (2009). Africa's urban transition and the role of regional collaboration. Nueva York: Institute for International Economics and Development-IIED.

Meadows, D., Meadows, D., Randers, J. y Behrens, W. (1972). Los límites del crecimiento. México D. F.: Fondo de Cultura Económica.

Milchan, A. (productor) y Guilliam, T. (director). (1985). Brazil [cinta cinematográfica]. UK: Embassy International Pictures.

Molina-Prieto, L. (2016). Resiliencia a inundaciones: nuevo paradigma para el diseño urbano. Revista de Arquitectura, 8(2), 82-94. 
Molina-Prieto, L. y Garzón, M. (2017). Propiedades de concretos y morteros modificados con nanomateriales: estado del arte. Arquetipo, 14, 81-98.

Molina-Prieto, L. y Cortes, O. (2014). Materiales compuestos para la arquitectura recursos e impacto ambiental. Revista de investigación, 7(2), 153-173.

Morris, A. (1984). Historia de la forma urbana desde sus orígenes hasta la revolución industrial. Barcelona, España: Gustavo Gili.

Nevens, F., Frantzeskaki, N., Gorissen, L., y Loorbach, D. (2013). Urban transition labs: co-creating transformative action for sustainable cities. Journal of Cleaner Production, 50, 111-122. DOI: https://doi.org/10.1016/j.jclepro.2012.12.001

Osborn, H. (1948). Our plundered planet. Nueva York: Little, Brown.

Pannell, C. (2002). China's continuing urban transition. Environment and Planning A, 34(9), 15711589. DOI: https://doi.org/10.1068/a34201

Pommer, E. (productor), y Lang, F. (director). (1927). Metrópolis [cinta cinematográfica]. Alemania: UFA.

Rondinelli, D. A. (1986). The Urban Transition and Agricultural Development: Implications for International Assistance Policy 1. Development and Change, 17(2), 231-263.

Schmidt-Kallert, E. (2009). A new paradigm of urban transition: Tracing the livelihood strategies of multi-locational households. Die Erde, 140(3), 319-336.

Spivak, G. (1988). Can the subaltern speak? En C. Nelson y L. Grossberg (Eds.), Marxism and the Interpretation of Culture (pp. 66-111). Londres, UK: Macmillan.

Rifkin, J. (1994). The end of work: the decline of the global labor force and the dawn of the post-market era. New York: Tarcher/Perigee.

Rifkin, J. (2011). The third industrial revolution. Nueva York: Palgrave Macmillan.

Rifkin, J. (2000). The age of access. Nueva York: Tarcher/Perigee.

Urteaga, L. (1985). Higienismo y ambientalismo en la medicina decimonónica. Acta Hispanica ad Medicinae Scientiarumque Historiam Illustrandam, 5-6, 417-425. 